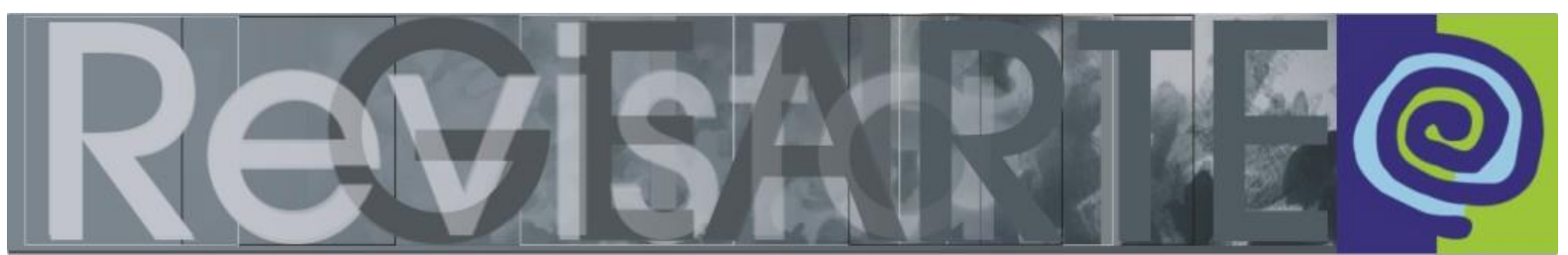

ISSN 2357-9854 | e-ISSN 2596-3198 (online)

\title{
Além dos muros da escola
}

\author{
Jéssica Makino (iD \\ (Universidade de São Paulo — USP, Ribeirão Preto/SP, Brasil)
}

\begin{abstract}
RESUMO - Além dos muros da escola - Este trabalho resulta das reflexões geradas a partir das experiências com expedições culturais realizadas com turmas do curso de Pedagogia. Autores como Paulo Freire, Mirian Celeste Martins, Boaventura de Souza Santos, Celestin Freinet e Murray Schafer ampararam a prática e as reflexões decorrentes dela. $O$ texto descreve as ações de preparação, realização e avaliação das expedições culturais, os métodos de registro das experiências bem como os debates realizados a posteriori. Dessas ações, resulta a reflexão a respeito dos espaços de difusão cultural como espaços não formais de ensino, bem como a importância de acesso como forma de borrar as linhas abissais que separam estratos sociais.
\end{abstract}

\section{PALAVRAS-CHAVE}

Expedição cultural. Espaço não formal de ensino. Registro. Linhas abissais em arte.

ABSTRACT - Beyond the school walls - This work is a result of personal reflections generated from experiences with cultural expeditions carried out with groups from the Pedagogy course. Authors such as Paulo Freire, Mirian Celeste Martins, Boaventura de Souza Santos, Celestin Freinet and Murray Schafer supported the practice and the reflections arising from it. The text describes the preparation, execution and evaluation of the cultural expeditions, the methods used to register document their experiences, as well as the discussions that took place thereafter. From these activities arises a reflection about spaces for cultural diffusion such as non-formal teaching spaces, as well as the importance of accessibility to these spaces as a way to blur the abyssal lines that separate social strata.

\section{KEYWORDS}

Cultural expedition. Non-formal teaching space. Documentation. Abyssal lines in art.

RESUMEN - Más allá de los muros de la escuela - Este trabajo es el resultado de las reflexiones generadas a partir de las experiencias de las expediciones culturales realizadas con las clases del curso de Pedagogía. Autores como Paulo Freire, Mirian Celeste Martins, Boaventura de Souza Santos, Celestin Freinet y Murray Schafer apoyaron la práctica y las reflexiones derivadas de ella. El texto describe la preparación, realización y evaluación de las expediciones culturales, los métodos de registro de las experiencias, así como los debates que tuvieron lugar posteriormente. De estas acciones resulta la reflexión sobre los espacios de difusión cultural como espacios de enseñanza no formal, así como la importancia del acceso como forma de desdibujar las líneas abisales que separan los estratos sociales.

\section{PALABRAS CLAVE}

Expedición cultural. Espacio de enseñanza no formal. Registro. Líneas abisales en el arte. 


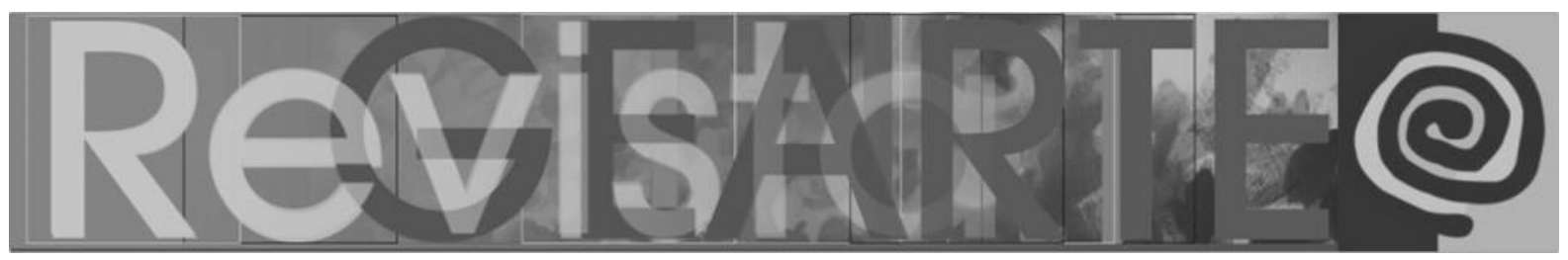

\section{Introdução}

Neste trabalho apresento reflexões acerca de experiências vividas como docente ao ministrar a disciplina Arte e Música na Educação, componente curricular obrigatório do curso de Licenciatura em Pedagogia Faculdade de Filosofia, Ciências e Letras de Ribeirão Preto da Universidade de São Paulo (FFCLRP-USP) ${ }^{1}$. Dessas experiências, relato a importância das expedições culturais, bem como os relatos dessas vivências.

O objetivo do curso de Licenciatura em Pedagogia da FFCLRP-USP é formar professores/as que atuarão na Educação Infantil e nas séries iniciais do Ensino Fundamental (primeiro ao quinto ano) e que também serão capazes de trabalhar com gestão educacional. Em sua formação inicial, a/o pedagoga/o deve conhecer as linguagens das artes visuais e da música, tendo experimentado diferentes vivências de criação, entrado em contato com obras de arte em espaços expositivos e salas de música, realizado exercícios de mediação e planejamentos de proposições artísticas. A partir dessas experiências e do estudo de referenciais teóricos, espera-se que a/o pedagoga/o defenda a importância do ensino de arte na educação e possa atuar em parceria com a/o professor/a especialista de arte ou música.

Levar os/as estudantes para trabalhos em campo é uma ação comum dentro da universidade, muito valorizada por docentes e estudantes, dada a qualidade do conhecimento construído nesse tipo de ação. Em minha instituição, essa atividade é denominada excursão didática, passeio cultural ou visita cultural. Na disciplina Arte e Música na Educação, adotei o nome expedição cultural, conceito apresentado por Mirian Celeste Martins na publicação Horizontes culturais da Secretaria Estadual de Cultura de São Paulo, em 2008. Essa escolha não se tratou somente de opção terminológica, mas, também, de escolha metodológica.

A nomenclatura "passeio cultural" pode ser erroneamente interpretada como proposta de um momento de relaxamento e de entretenimento, de oportunidade 


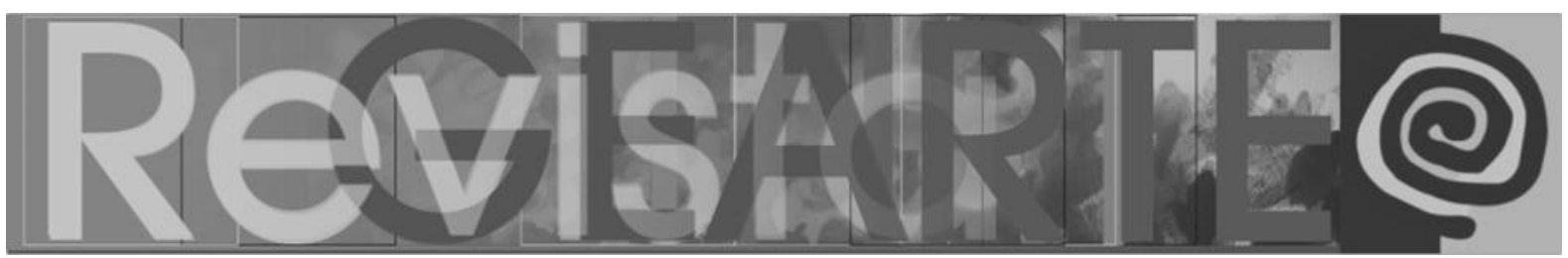

de convívio e de alívio das tensões geradas pelos estudos na graduação. Embora esses sejam motivos louváveis para cruzar os portões da universidade, em termos de construção de conhecimento, acredito que a expedição cultural exige, do sujeito, uma postura de investigação, olhar atento, disposição para responder a perguntas elaboradas antes de partir, como: o que será investigado nessa expedição? Há protocolos de conduta? Quais são as ferramentas de registro que utilizarei? Como compartilhar o que aprendi com essa experiência?

As expedições culturais são inspiradas nas expedições científicas realizadas por Charles Darwin antes de elaborar o histórico texto $A$ Origem das Espécies (SÃO PAULO, 2008, p. 19-20). Nas expedições científicas, o/a cientista dirige-se ao campo preparado/a para observar e registrar o meio, munido/a de olhar investigativo. Martins lembra que, na época, faziam parte das expedições artistas como Rugendas, Adrien Taunay e Hercule Florence, por exemplo, que documentavam visualmente a fauna, a flora e a cultura local. A expedição científica, em sua raiz, foi organizada para ter artistas como profissionais que registram o meio estudado, pessoas que realizavam interpretações de um ambiente desconhecido e, nesse sentido, a expedição cultural herda, não somente os procedimentos da expedição científica, mas, também, o olhar artístico no registro da experiência.

A metodologia da expedição cultural que escolhi desenvolver na FFCLRPUSP encontra consonância não somente nas expedições científicas como também na aula-passeio de Celestin Freinet (1896-1966) (ELIAS; SANCHES, 2007, p. 166)). A proposição de Freinet nasce a partir da observação das crianças e de seus interesses, concentrados na vida que se desenvolvia fora da sala de aula e longe dos livros didáticos. Nas aulas-passeio, os/as estudantes observavam, nos espaços urbanos, as ações dos trabalhadores em suas variadas profissões, as relações entre as pessoas, os modos de organização espacial; no campo, observavam as transformações da natureza de acordo com as mudanças das estações. As experiências vividas eram recuperadas no retorno à escola, conversadas, sistematizadas nos seus vários saberes em forma de resumos da 


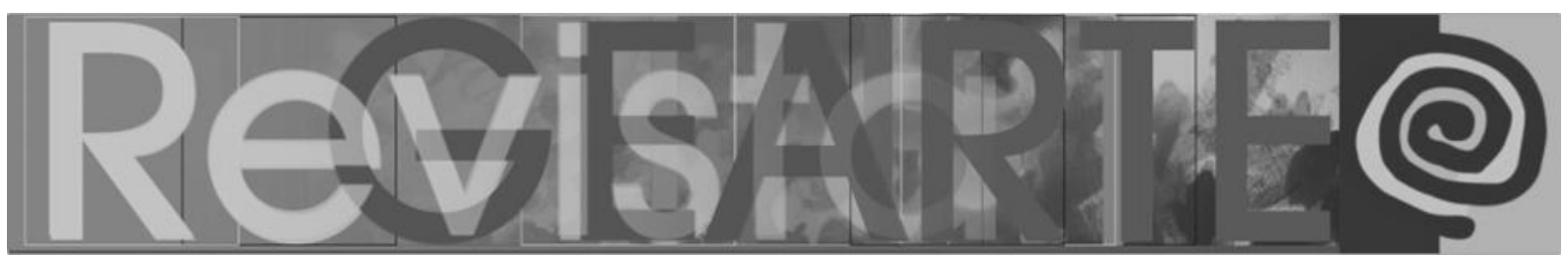

experiência escritos no caderno e desenhos que registravam as várias experiências (SAMPAIO, p. 17-21). Como nas expedições científicas, nas aulaspasseio, uma das formas de registro da experiência, era o desenho das crianças.

Em suma, a investigação de mundo da expedição cultural no viés adotado inspira-se na metodologia de cientistas (biólogos, antropólogos, geógrafos, historiadores) e nas ações de educação antes de ser uma proposta metodológica da área de arte. Ao mesmo tempo, está imbuída do olhar artístico em todas as suas versões, seja na investigação e na experimentação, que são ações da arte e da ciência, seja nos registros visuais feitos pelos artistas que faziam parte das equipes de expedição científica, ou nos desenhos realizados pelas crianças, estudantes de Freinet.

\section{A escolha dos lugares}

A escolha dos locais para a realização da expedição cultural é realizada pelo grupo, seguindo critérios. Primeiro, como a disciplina cursada envolve duas linguagens artísticas, escolhemos um local para estudar música e outro para estudar artes visuais. Dentre os espaços não formais de ensino da cidade de Ribeirão Preto, optamos por instituições de manutenção pública e/ou privada que têm preocupação com a qualidade de seu acervo e da ação educativa e que dispõem de acesso gratuito. Por essa razão, foram escolhidos o Museu de Arte de Ribeirão Preto, o Instituto Figueiredo Ferraz e o Theatro Pedro II. Para os espaços da cidade de São Paulo, além dessas condições, determinamos, como critério, a escolha de lugares que as/os estudantes normalmente não visitariam em viagens turísticas à cidade.

O estabelecimento dessa última condição deu-se na interação com uma das turmas. Realizamos a indicação e votação das instituições candidatas a serem foco de expedição por meio de um aplicativo de trocas de mensagens. Os locais indicados pelas/os estudantes eram turísticos e variados, localizados na região da Avenida Paulista, mas, por serem muitas sugestões, não era possível estabelecer 


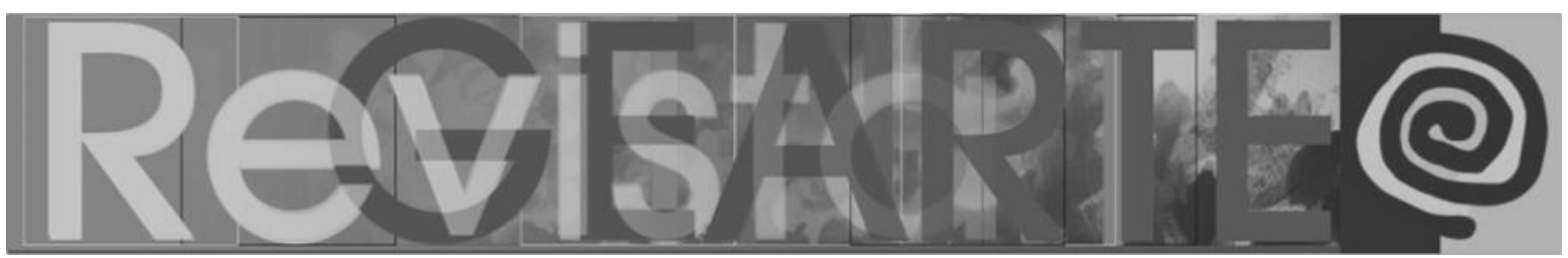

consenso. A expedição à São Paulo deveria ser uma oportunidade de conhecer locais que não pertencem ao circuito turístico mais popular e comercial. Por isso, foram escolhidas a Sala São Paulo e a Pinacoteca Estação, que têm sido espaços pouco convidativos, por conta da degradação do bairro onde estão localizadas.

Ida

Nas aulas que precederam as expedições, foram realizadas as preparações das/dos estudantes com informações a respeito dos espaços que seriam estudados, as obras expostas e o que se poderia esperar da vivência. Como estratégia para ajudar as/os estudantes em sua investigação de campo, esta docente elaborou dois roteiros com perguntas (um de Música e outro de Artes Visuais) que foram disponibilizados no drive virtual da disciplina.

Parte dessas preparações foi constituída de apreciação mediada de uma obra de arte que estava em exibição no museu, bem como a observação dos aspectos históricos e arquitetônicos do lugar. As imagens foram acessadas na internet no site do próprio espaço, quando disponível, ou de outras fontes, quando não acessível no site do museu. Do repertório dos concertos, foram escolhidos excertos que explicitavam os temas das obras, para que pudessem ser reconhecidos durante a apresentação. Na existência de análises, vídeos ou podcasts a respeito, esses foram compartilhados às/aos estudantes. 


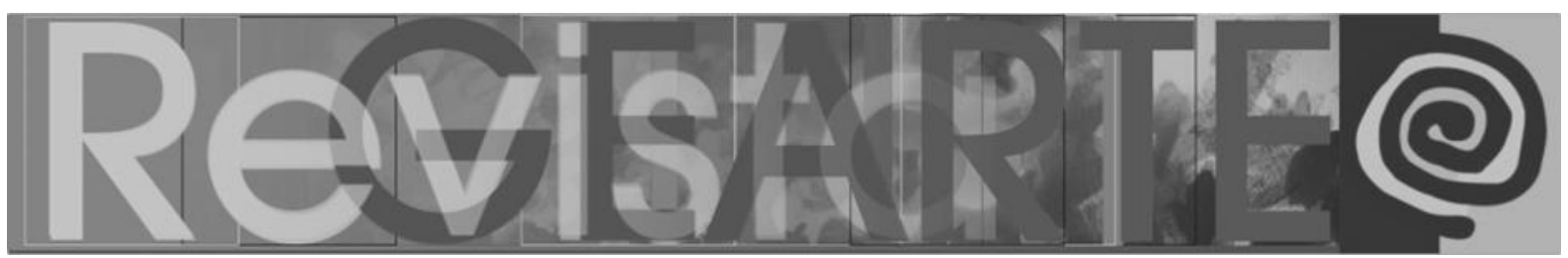

\section{0 roteiro de Música}

O Roteiro de Música continha desafios para serem realizados solitariamente ou em grupo, como explorar um ambiente realizando testes de som:

- Descubra a sala de espelhos.

- Experimente bater uma palma (ou estalar os dedos) nos vários espaços que você vai visitar (saguão de entrada, café, banheiro, sala de concerto, entre outros). Anote como o espaço responde acusticamente ao seu estímulo sonoro.

Perguntas relacionadas aos rituais do concerto, como:

- Onde se senta o spalla² da orquestra? O que ele faz?

- Como se dá a entrada do maestro? A quem ele se dirige?

- Observe os músicos. Todos se sentam da mesma maneira?

- Como os músicos lidam com a partitura? Cada um tem a sua? Quem muda a página? Alguém toca de memória?

Perguntas relacionadas ao repertório e à experiência musical, como:

- Cante os temas que o maestro apresentará a você.

- Todos os músicos tocam ao mesmo tempo? Caso não toquem, quais famílias de instrumento tocam mais? O que fazem quando não estão tocando?

- Quais famílias de instrumentos musicais tocam com maior volume sonoro?

- Há algum padrão na movimentação e respiração dos músicos? 


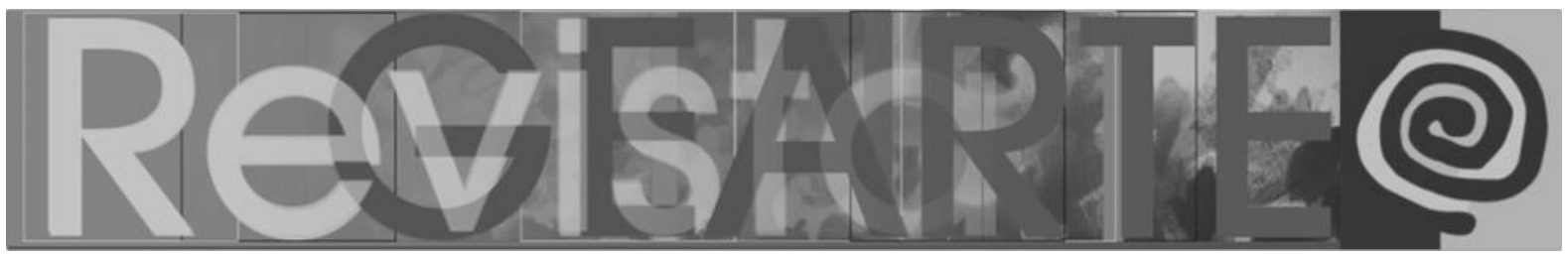

E perguntas relacionadas às impressões da experiência:

- É a sua primeira vez em um teatro de ópera?

- Qual a diferença entre esse teatro e outros espaços coletivos (cinema, teatro, estádio de futebol, igreja)? Quais forma suas sensações nesse lugar?

As perguntas que remetem às experiências acústicas têm, como referência, as experiências sonoras sugeridas pelo compositor canadense Raymond Murray Schafer (2011), previamente experimentadas em aula. A ideia de descobrir e experimentar segue o tom lúdico existente não somente nas propostas educacionais de Schafer, mas também nas suas próprias composições. Houve a preocupação de evidenciar às/aos estudantes os ritos e protocolos que fazem parte da vivência musical, ressaltando a ideia de que a experiência em sala de concerto extrapola a escuta, envolvendo a apreciação de um espetáculo que também é visual e performática.

\section{O Roteiro de Artes Visuais}

O Roteiro de Artes Visuais enfoca a relação entre a obra de arte e o/a graduando/a. Como mencionado anteriormente, nas aulas que antecedem a expedição, é feita a preparação para a saída, com exercícios de apreciação de algumas obras que fazem parte da exposição corrente no momento da visitação. Durante a visitação, peço para que o/a estudante escolha uma obra para se conectar e realizar as apreciações solicitadas no roteiro:

- Diga quais foram as suas primeiras impressões em relação a ela, diga o que sentiu e pensou quando a viu;

- Fale de suas impressões após a mediação da monitoria; 


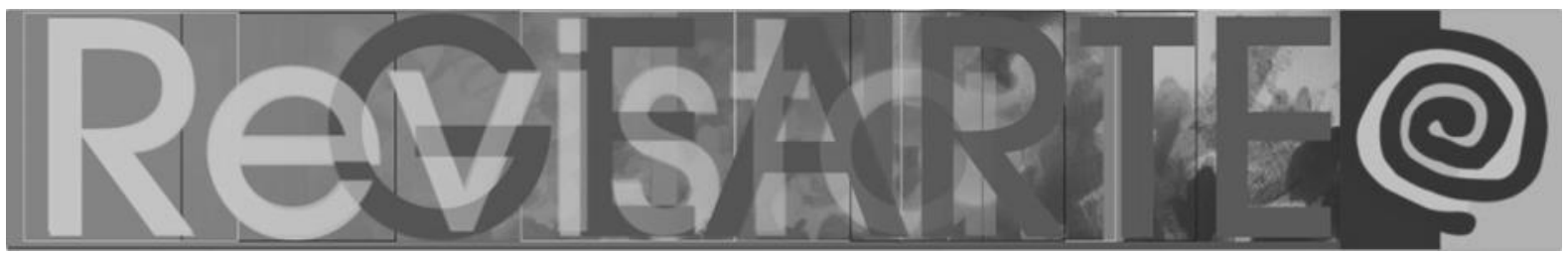

Perguntas em relação aos aspectos formais da obra, como:

- Descreva as características do suporte da obra, as técnicas e os materiais utilizados;

- Fale um pouco sobre as dimensões da obra. Como você, em sua presença, se relaciona com as dimensões da obra?

E de como se relaciona com os trabalhos que estão ao seu redor:

- Opine sobre a posição da obra em relação às demais. Por que acha que a obra escolhida está posicionada no local onde se encontra?

- Você enxerga alguma conversa entre a obra escolhida e as demais?

Por último, perguntas a respeito das escolhas e das impressões:

- Agora diga por que escolheu essa obra para ser lida.

- Fale de qual obra menos gostou ou qual obra menos o(a) tocou e por quê.

\section{Volta}

A aula que sucede a expedição é iniciada com uma roda de conversa, em que partilhamos as descobertas, as inquietações e refletimos como essas expedições poderão ser realizadas com as crianças, no futuro. Da vivência da expedição, faz-se necessário o registro na forma de relatório, que pode ser realizado em duplas ou trios. O trabalho em conjuntos pequenos é preferível ao trabalho solo, para que haja conversa entre as pessoas que participaram da experiência de registro e de reflexão, para provocar, assim, discussão e realização de acordos, tanto a respeito do que relatar, quanto sobre o como relatar. Ou seja, o trabalho em grupo requer o exercício de princípios básicos de convivência democrática, inclusive para a escrita do documento. Apesar dos benefícios da 


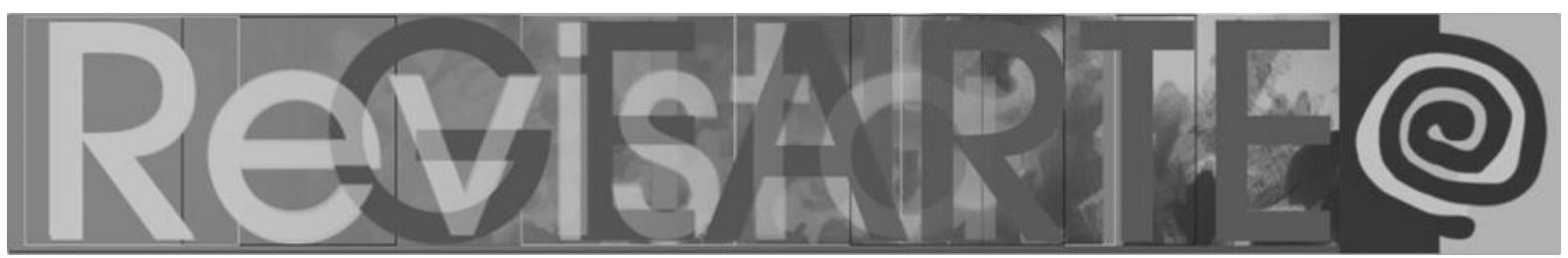

escrita conjunta, os relatos de experiência escritos solitariamente não são recusados, respeitando a liberdade de escolha de cada estudante. Nos relatos, espera-se que a/o estudante descreva não somente aspectos objetivos de sua experiência, como, também, impressões e sensações a respeito de sua interação com o espaço (museológico ou musical) e com as obras de arte.

Outra ferramenta de registro, além do relatório, é o uso das câmeras fotográficas contidas em smartfones. As câmeras são utilizadas tanto para registrar as obras observadas, quanto para registrar a presença dos/das estudantes nesses espaços. Contudo, as fotografias utilizadas para registro não são banais, pois revelam sensibilidade e critérios da/o fotógrafa/o nas escolhas de dimensões, de proporções, de planos e de enquadramentos do que deve ser considerado figura e o que deve compor o fundo. Como o desenho dos artistas que compunham as expedições científicas de Darwin e os desenhos das crianças feitas pós-aulapasseio de Freinet, neste trabalho, as fotografias também são consideradas registros artísticos.

Muitas/os estudantes, utilizando de linguagem contemporânea praticada em mídias sociais como Instagram e Facebook, utilizaram a modalidade selfie como forma de registro. Com o Grupo de Pesquisa Arte na Pedagogia (GPAP), o qual faço parte, aprendi com professoras que utilizam esse tipo de registro de modo sistemático, a compreender o selfie como uma ferramenta legítima de documentação. Incentivo, também, que essas imagens sejam postadas nas mídias sociais dos estudantes, para que os espaços sejam divulgados às pessoas relacionadas às/aos estudantes.

Divulgar os registros dessas experiências nas mídias sociais é uma forma de firmar posição em locais que, a princípio, poderiam parecer inacessíveis, como a Sala São Paulo, por exemplo. Essa é uma forma de se apoderar do espaço, de firmar presença nos locais, de se incluir na composição de algo muito valioso, que são os espaços de divulgação e apreciação de arte. Além disso, outra função da divulgação dos registros é o compartilhamento dessa experiência com pessoas 


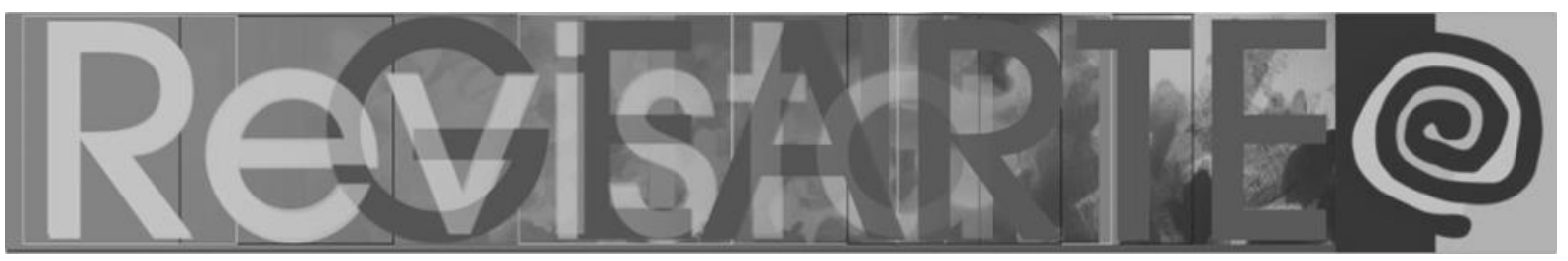

que nunca poderiam pensar que esses lugares poderiam ser acessíveis ou ser passíveis de visitação.

Figura 1 - Foto de Aline Monti, Ana Júlia Cristal e Sarah Beirigo

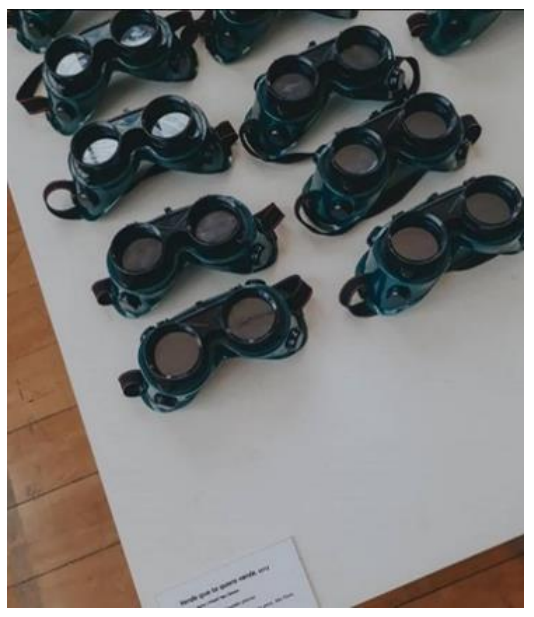

Fonte: Arquivo de Aline Monti, Ana Júlia Cristal e Sarah Beirigo (2019).

Figura 2 - Selfie de Thaís Raquel Alves de Souza

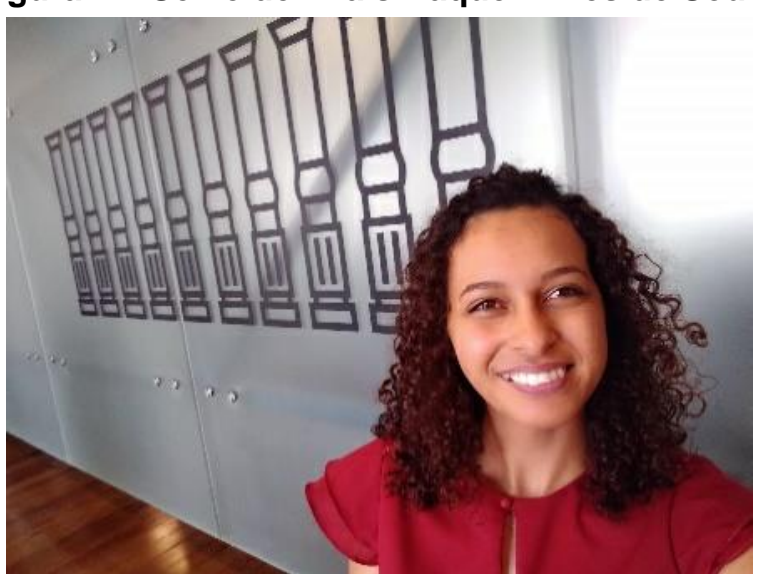

Fonte: Arquivo de Thaís Raquel Alves de Souza (2019)

\section{A importância da escrita}

A escrita é uma ferramenta de registro imprescindível a esses/as futuros docentes e, nas atividades de arte e música, não poderia ser considerada ferramenta secundária. A importância da escrita, para Paulo Freire, está no processo dialógico que se desenvolve quando o/a educando/a se confronta com o seu pensamento posto em palavras. Essas, por sua vez, formam-se no trabalho, na interação com o mundo na vida e na ação: "não é no silêncio que os homens se fazem, mas na palavra, no trabalho, na ação-reflexão" (FREIRE, 2005, p. 90). 


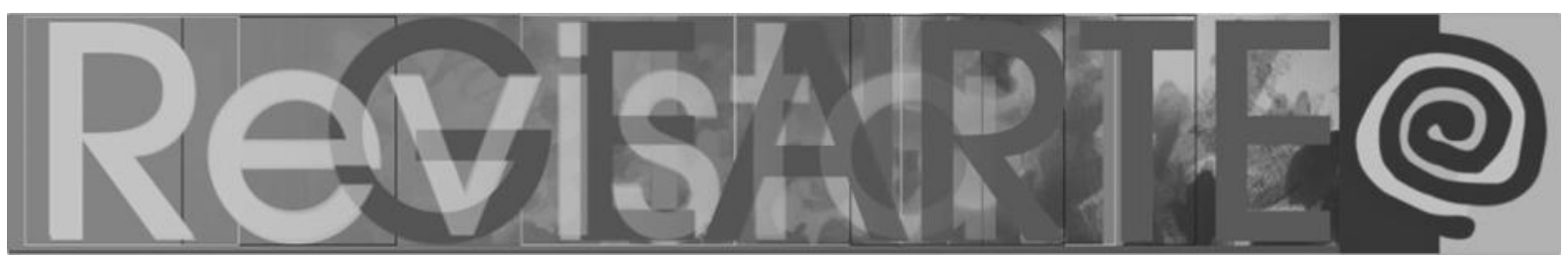

A importância do registro escrito para a promoção da reflexão faz-se necessária, também na conduta metodológica do/a professor/a que está em formação inicial. A escrita é uma ação dialógica, prática do sujeito que leva à ponderação, registro de uma vivência que pode ser retomada no futuro, é memória e pensamento. Ao mesmo tempo, é ferramenta metodológica e, quando se planeja que os/as graduandos/as realizem a narrativa escrita das expedições, espera-se que exercitem, desde sua formação inicial, a prática desse instrumento metodológico. A partir desses documentos, é possível avaliar tanto os conhecimentos construídos a partir da expedição quanto as estratégias de preparação, mediação e avaliação das expedições culturais.

\section{Relatórios e relatos}

Foi minha primeira experiência em um concerto e em um teatro artístico como este, é um lugar bem arranjado com acústica estudada. Foi muito interessante esse contato com a música, de uma forma presencial, de sentir os instrumentos sendo tocados, as vibrações, foi uma experiência sensacional e com certeza indicaria pra mais pessoas passarem por ela, assim como eu gostaria de participar por outras, mas diferentes, sempre aberto a novas experiências. (DALPOGETO, 2018, p. 2)

[...] embora já conhecesse o teatro e tenha ido em eventos ocorridos nele, nunca havia ido para ouvir um Concerto. A perspectiva sobre o espaço foi se modificando à medida que a atmosfera criada pela orquestra ia se instaurando. Diferente de outros espaços coletivos o teatro me deu a impressão transcendental. As emoções a flor da pele vibram ao soar dos instrumentos, gerando uma excitação que nos leva para um imaginário de tempos áureos da história. (MANOELI, 2018, p. 5)

Os trechos dos relatórios selecionados acima mostram a importância da experiência in loco, no caso, a experiência musical em um espaço construído para isso. A emoção do primeiro concerto, a sensação de reconhecer algo novo em instalações já conhecidas, o imaginário em relação às histórias contidas naquele local. Além desses, outros aspectos da experiência são manifestados, como relato a seguir.

Uma das expedições aconteceu no Dia dos Pais e, por esse motivo, membros das famílias acompanhavam a turma. Ao final do concerto, o pai de uma das estudantes me procura para agradecer a oportunidade de conhecer por dentro 


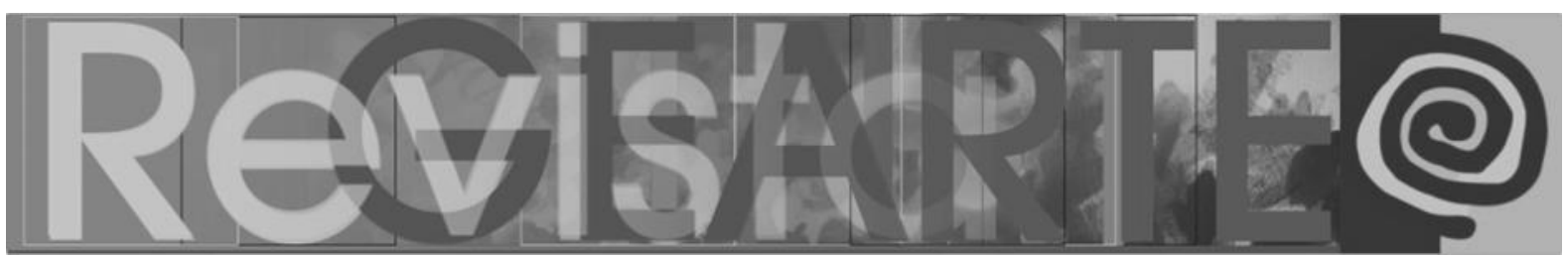

o teatro que via de seu escritório há mais de vinte anos. Perguntei por que não tinha entrado antes: não tive a oportunidade - foi a resposta. Mas os concertos matinais são gratuitos, qual seria a oportunidade perdida? Desconhecer a gratuidade? Falta de divulgação?

Em relação a outro espaço de expedição, o Museu de Arte de Ribeirão Preto, várias falas dos/das estudantes estavam relacionadas ao desconhecimento do lugar e da possibilidade de ser um local propício para uma atividade cultural alternativa aos parques e shoppings centers. Como o museu, localizado no centro da cidade, com alta circulação de transeuntes é despercebido pelas pessoas? Ou será que, de certa forma, as pessoas não considerem o Museu e o Theatro, locais oportunos para visitação?

\section{Linhas abissais}

Boaventura de Souza Santos (2007) denomina linhas abissais as demarcações territoriais invisíveis que separam um grupo social de outro. Essa separação, por ser abissal, não só delimita os espaços, mas, também, o pensamento e a identidade, promovendo a exclusão pelo apagamento e pela invisibilidade. A linha abissal nos espaços da cidade demarca o apagamento desses locais culturais para os grupos que, socialmente, não se ajustariam a esses espaços. O Museu de Arte de Ribeirão Preto é localizado no prédio do antigo salão de baile da cidade, marcadamente frequentado pela elite econômica local. Apesar da localização ser no centro da cidade, próximo aos terminais de ônibus, a sua arquitetura, sua história e, talvez, a sua antiga função de abrigar os bailes da elite local, indiquem aos transeuntes comuns que não é um local acessível a todos. Para uma grande camada da população, arte considerada erudita não é destinada a todos e, nesse sentido, um espaço como o MARP e o Theatro Pedro II são espaços reservados para a elite econômica que viria a ser, também, a elite cultural.

A parte menos favorecida da população, que costuma ter sua presença invisibilizada, então, tem para si o apagamento dos espaços destinados à camada 


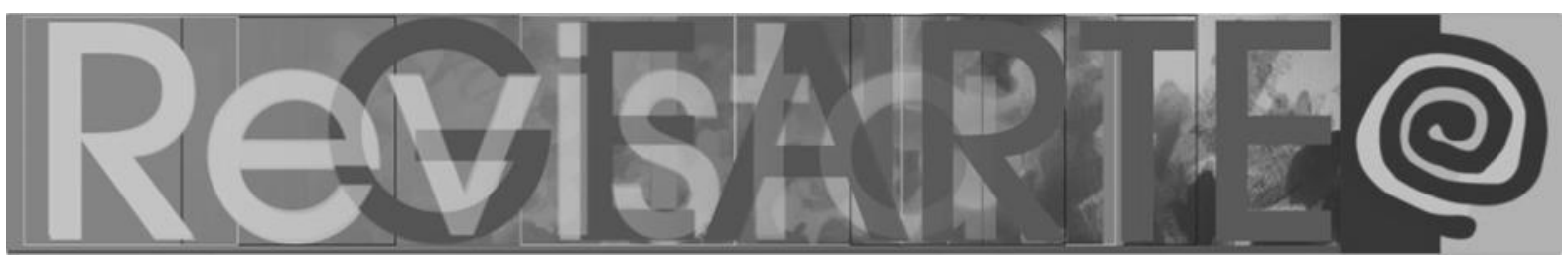

mais favorecida da sociedade. Isso é evidente nas falas e relatos: não sabia que havia outros lugares para passear em Ribeirão Preto além dos shoppings centers e parques. Há, contudo, um esforço, dentro das instituições, para acolher toda a sociedade, tanto que as ações educativas das duas estão preparadas para isso. Por alguma razão, entretanto, a possibilidade de penetrar nesses lugares parece não chegar às camadas menos favorecidas da população. O não saber e a falta de oportunidade podem indicar, não a falta de divulgação, mas a falta de permissão de entrada aos espaços marcados socialmente como pertencentes à elite.

Essas barreiras ficaram muito evidentes na expedição realizada em São Paulo, na Sala São Paulo e na Pinacoteca Estação. Ambos os espaços culturais estão situados em um bairro degradado da região central da cidade, apelidada de cracolândia. As ruas do bairro estão tomadas por pessoas doentes pelo consumo de drogas, andando a esmo ou concentradas nas "feirinhas" - barracas onde se comercializam essas drogas. Além delas, famílias e guardas municipais compartilham as ruas e calçadas.

No interior da Sala São Paulo, vivencia-se o deslumbramento pelas tecnologias empregadas no tratamento acústico, as soluções arquitetônicas que harmonizam a estética do século XIX com a do século XXI, ao luxo do espaço, aos cuidados (concierge, chapelaria). Não é possível reconhecer nenhuma das pessoas que compartilham o espaço exterior no espaço interior. O mesmo foi perceptível na expedição à Pinacoteca Estação.

O contraste existente entre o espaço interno e o externo não foi desapercebida pelos/as estudantes em expedição com os quais discutimos a violência presente nos ambientes investigados: a quem está sendo destinada? Aos visitantes dos espaços culturais? Aos moradores dos prédios? Aos moradores em situação de rua?

A Pinacoteca Estação, que faz parte da Pinacoteca do Estado e é um museu de artes visuais, engloba o Memorial da Resistência, onde se resguarda a memória 


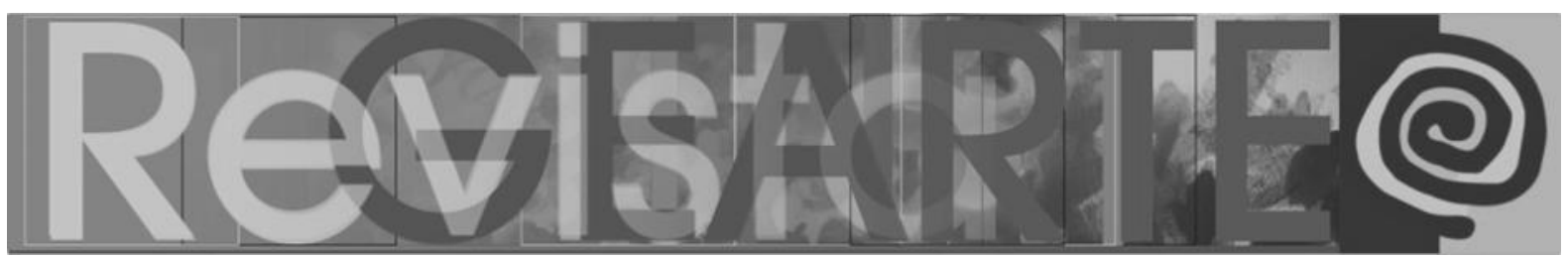

dos anos de ditadura militar. Nesse lugar, que foi um centro de repressão, o educador que realizou a medição questiona: o que é tortura? Há tortura nos dias de hoje? Quem sofre tortura? A depender em que lado da linha abissal estamos situados, a resposta será sim, há tortura hoje, ou não, não existe tortura. Aos que estão em situação de rua, transitando nas ruas da cracolândia, a tortura é diária. Aos que vivem em moradas provisórias, longe do trabalho e sem segurança e saneamento básico, a tortura também é diária. Qual é o papel da arte e do/a professor/a em um lugar onde a tortura acontece pelas diferenças sociais?

Essa situação impactante, provocou uma série de reflexões às/aos estudantes, que levaram para a apreciação das obras as situações vivenciadas no lado de fora das construções. As descobertas e os saberes resultantes da investigação das obras em exibição, da realidade interna e externa dos espaços culturais refletem da seguinte forma nesse relatório:

\begin{abstract}
O conjunto das obras que me chamou atenção chama-se "A margem" e traz por meio de imagens e arquiteturas históricas a luta de grupos sociais marginalizados da cidade de São Paulo a partir das sucessivas tentativas de apagamento físico e simbólico do rio Tamanduateí - entidade sagrada para as populações originarias que - ao longo da história da cidade, abrigou e abriga diversas formas de resistência em suas margens. As imagens e obras estavam localizadas perto de uma janela imensa, onde de longe eu consegui ver pessoas que também estavam marginalizadas da cidade de São Paulo, e ainda sim, resistindo (DEHN, 2019, p. 1).
\end{abstract}

\title{
Figura 3 - Foto de Camila Galvão de Freitas
}

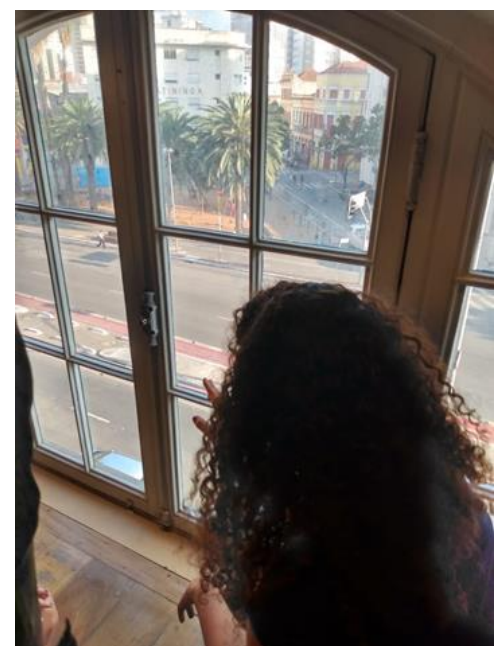

Fonte: Arquivo de Camila Galvão de Freitas (2019). 


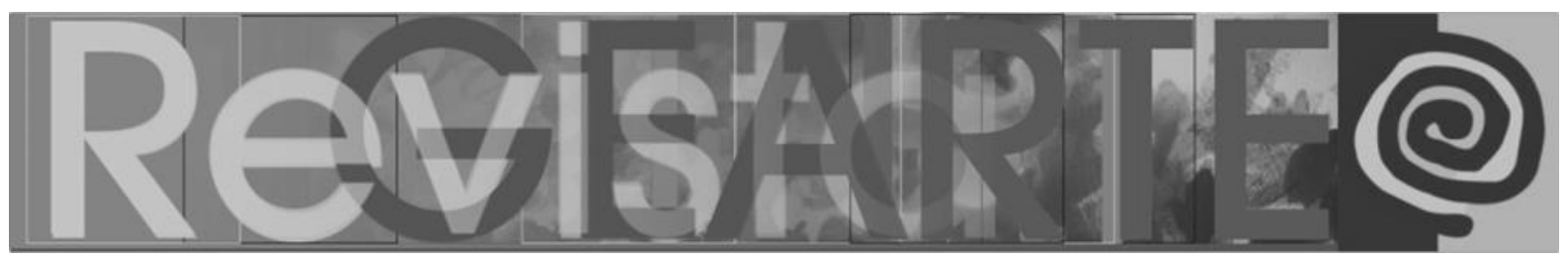

\section{Considerações finais}

Além dos muros da escola engloba todos os espaços que envolvem a localidade. São os espaços investigados pelos/as estudantes de Celestin Freinet: as regiões urbanas e rurais, os lugares estabelecidos para o relacionamento entre pessoas e o relacionamento entre natureza e seres humanos.

Nesse sentido, além dos muros da universidade contempla os espaços de difusão cultural, as ruas e calçadas que nos levam a esses lugares, as relações entre as pessoas que frequentam os arredores e que podem ou não transitar por todos os espaços. Penetrar os espaços expositivos e os espaços da arte e da música, é uma forma de trazê-las de volta à vida cotidiana e esse é um dos papéis da universidade e da escola. Os prédios dos espaços de difusão cultural não podem ser relegados a serem pontos de referência, precisam ser parte do cotidiano de todos os sujeitos que habitam a cidade.

As investigações proporcionadas pelas expedições são transformadoras, no sentido de desvelar e de evidenciar os espaços em que há produção e difusão de arte, de possibilitar a conexão entre obra de arte e graduandas/os que promoverão a multiplicação da vivência, conduzindo suas famílias e amigos a esses lugares, para reviverem e compartilharem a experiência. Além disso, esses/as são futuros/as professores/as que, potencialmente, levarão estudantes às expedições culturais em ações que possam borrar linhas abissais.

\section{Notas}

1 Para a realização dessas experiências contei com a contribuição do professor contratado II Humberto Muniz.

2 Spalla significa ombro em italiano e é onde o violinista apoia o seu instrumento. Na orquestra, o spalla é o primeiro violinista, é o "ombro" no qual o maestro e grupo podem se apoiar.

\section{Referências}

DALPOGETO, João Lucas. Relatório de escuta. Ribeirão Preto - SP: Faculdade de Filosofia, Ciências e Letras de Ribeirão Preto da USP, 2018. Relatório de expedição cultural da disciplina Arte e Música na Educação do curso de Pedagogia. 


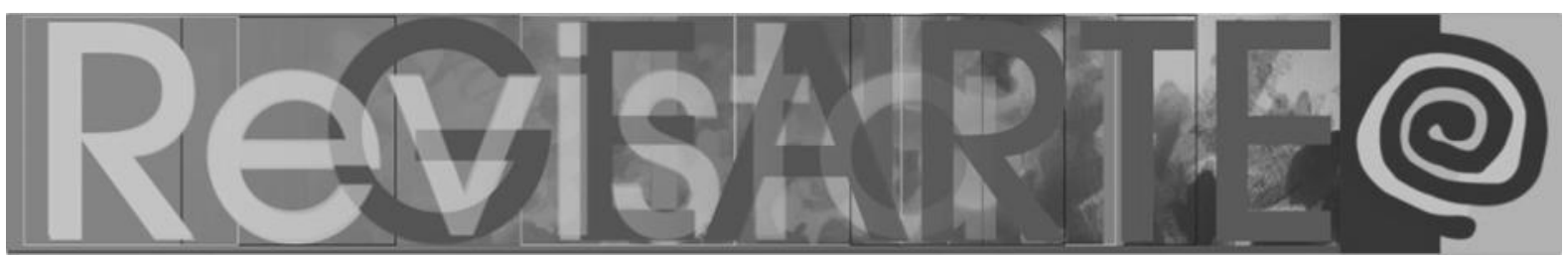

DEHN, Heloísa. Relatório de expedição. Ribeirão Preto - SP: Faculdade de Filosofia, Ciências e Letras de Ribeirão Preto da USP, 2019. Relatório de expedição cultural da disciplina Arte e Música na Educação do curso de Pedagogia.

FREIRE, Paulo. Pedagogia do oprimido. Rio de Janeiro: Paz e Terra, 2005.

MANOELI, Arielen Virgínia de Araújo dos Santos. Relatório de escuta. Ribeirão Preto - SP: Faculdade de Filosofia, Ciências e Letras de Ribeirão Preto da USP, 2018. Relatório de expedição cultural da disciplina Arte e Música na Educação do curso de Pedagogia.

ELIAS, Marisa Del Cioppo; SANCHES, Emilia Cipriano. Freinet e a pedagogia - uma velha ideia muito atual. In: OLIVEIRA-FORMOSINHO, Júlia; KISHIMOTO, Tizuko Morchida; PINAZZA, Mônica Appezzato (Orgs.). Pedagogia(s) da infância: dialogando com o passado: construindo o futuro. Porto Alegre: Artmed, 2007.

SAMPAIO, Rosa Maria W. F. Freinet: evolução histórica e atualidades. São Paulo: Scipione, 1989.

SÃO PAULO (Estado). Secretaria da Educação. Horizontes culturais: lugares de aprender. São Paulo: Fundação para o Desenvolvimento da Educação, 2008, 171 p.

SCHAFER, R. Murray. Educação Sonora. Tradução: Marisa Trench de Oliveira Fonterrada. São Paulo: Melhoramentos, 2011.

SOUZA SANTOS, Boaventura. Para além do pensamento abissal: das linhas globais a uma ecologia de saberes. Novos estudos CEBRAP, São Paulo, n. 79, p. 71-94, nov. 2007.

\section{Jéssica Makino}

Professora do curso de Pedagogia da Faculdade de Filosofia, Ciências e Letras de Ribeirão Preto /USP. Licenciada em Educação Artística com habilitação em Música, mestre e doutora em Música pela Universidade Estadual Paulista. Vice-líder do grupo de pesquisa Arte na Pedagogia (GPAP).

ORCID: https://orcid.org/0000-0001-8653-3550

E-mail: jmakino@usp.br

Currículo: http://lattes.cnpq.br/0929873470085756

Recebido em 24 de fevereiro de 2021

Aceito em 30 de abril de 2021 